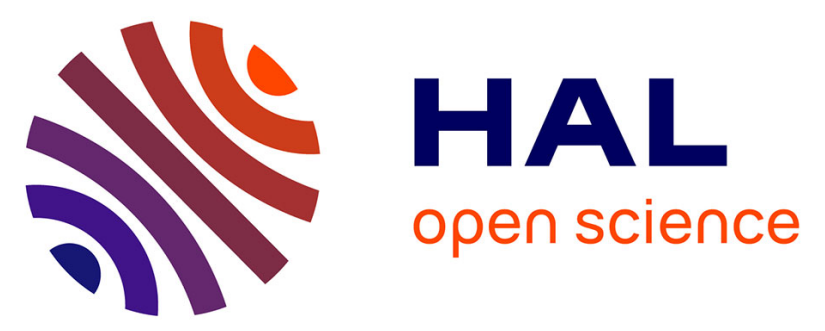

\title{
Landslide Observation from ALOS-2/PALSAR-2 Data (Image Correlation Techniques and Sar Interferometry). Application to Salazie Circle Landslides (La Reunion Island)
}

Daniel Raucoules, Fabrizio Tomaro, Michael Foumelis, Caterina Negulescu, Marcello de Michele, Bertrand Aunay

\section{To cite this version:}

Daniel Raucoules, Fabrizio Tomaro, Michael Foumelis, Caterina Negulescu, Marcello de Michele, et al.. Landslide Observation from ALOS-2/PALSAR-2 Data (Image Correlation Techniques and Sar Interferometry). Application to Salazie Circle Landslides (La Reunion Island). IGARSS 2018 - 2018 IEEE International Geoscience and Remote Sensing Symposium, Jul 2018, Valencia, France. pp.506509, 10.1109/IGARSS.2018.8517998 . hal-02734613

\section{HAL Id: hal-02734613 https://hal-brgm.archives-ouvertes.fr/hal-02734613}

Submitted on 2 Jun 2020

HAL is a multi-disciplinary open access archive for the deposit and dissemination of scientific research documents, whether they are published or not. The documents may come from teaching and research institutions in France or abroad, or from public or private research centers.
L'archive ouverte pluridisciplinaire HAL, est destinée au dépôt et à la diffusion de documents scientifiques de niveau recherche, publiés ou non, émanant des établissements d'enseignement et de recherche français ou étrangers, des laboratoires publics ou privés. 


\title{
LANDSLIDE OBSERVATION FROM ALOS-2/PALSAR-2 DATA (IMAGE CORRELATION TECHNIQUES AND SAR INTERFEROMETRY). APPLICATION TO SALAZIE CIRCLE LANDSLIDES (LA RÉUNION ISLAND)
}

\author{
Daniel Raucoules ${ }^{l}$, Fabrizio Tomaro ${ }^{2}$, Michael Foumelis ${ }^{l}$, Caterina Negulescu ${ }^{l}$, Marcello de Michele ${ }^{l}$, \\ Bertrand Aunay ${ }^{1}$,
}

1: BRGM, French Geological Survey, d.raucoules@ brgm.fr

2: University of Salerno

\begin{abstract}
In the presented study our purpose is to show the interest of space-borne high-resolution L-band Synthetic Aperture Radar (SAR) images (ALOS-2/PALSAR2 data in SM1 mode) for mapping deformation of slow landslides. The methods we combined are sub-pixel correlation offset tracking techniques and differential SAR interferometry. Hell-bourg and Grand Ilet landslides (our test cases) are located on La Réunion Island in the Indian Ocean with motions up to about $1 \mathrm{~m} / \mathrm{y}$. The produced deformation maps resulted better than those obtained in previous studies with $\mathrm{C}$ or $\mathrm{X}$ band SAR data or with current Sentinel-1 data as L-band data are less affected by the vegetated cover than $\mathrm{X}$ - or C-band data. Finally, the possibility of deriving 3D mapping of the displacement by combining ascending and descending acquisitions (each one provides 2 components of the deformation: line of sight and azimuth) is investigated.
\end{abstract}

Index Terms - InSAR, ALOS-2, Landslide

\section{INTRODUCTION}

Landslides are one of the geo-hazards with the most impact in terms of socioeconomic costs. Displacement monitoring of slope motions is therefore required to prevent and mitigate landslide risk.

The Salazie Circles on La Réunion Island (Indian Ocean) are affected by several landslides, including two major ones affecting the municipalities of Grand Ilet and Hell-bourg (Figure 1).

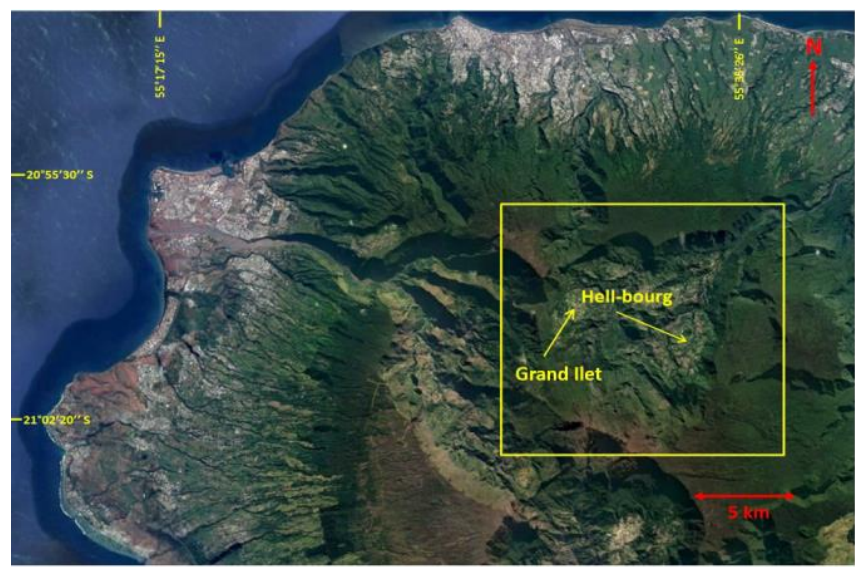

Figure 1: location of Salazie Circle (yellow frame)

The Hell-Bourg landslide is divided into three main panels, with average velocities increasing northward from 0.8 to $1.33 \mathrm{~m} / \mathrm{y}$ [1]. A previous study based on SAR Interferometry presented in [2] focused on the Hell-bourg landslide and showed the promise of using L-band data for interferometric purposes in the study area by comparing C-band RADARSAT (C-band) results and JERS-1 L-band data. The advantages of L-band data were twofold: due to the partially vegetated cover, L-band interferograms were significantly less affected by temporal decorrelation than those produced with RADARSAT data and the longer wavelengths are more adapted for the expected displacement ranges (several $\mathrm{dm} / \mathrm{y})$.

\section{METHODS}

\subsection{Used techniques}

In this study, we propose to use offset tracking based on local image correlation and Differential SAR interferometry (DInSAR) to derive deformation maps. For details on these techniques the reader can refer to [3-4]. Processing was carried out using GAMMA interferometric software. 
The final idea is to combine ascending and descending acquisition modes offset estimates and Line of Sight displacements estimates in order to obtain a better representation of the phenomenon. The procedure for combining the different components of the displacement is detailed in [5].

\subsection{Data}

Table 1 lists the ALOS-2/PALSAR2 acquisitions available for this study.

\begin{tabular}{cc}
\hline Ascending & Descending \\
\hline $2015-07-28$ & $2014-08-28$ \\
\hline $2015-10-06$ & $2014-10-23$ \\
\hline $2015-12-15$ & $2015-01-29$ \\
\hline $2016-07-26$ & $2015-08-13$ \\
$2016-10-04$ & $2015-09-24$ \\
\hline
\end{tabular}

Table 1: ALOS 2-PALSAR 2 data

Ascending data is acquired in SM3 (3.8m azimuth sampling) mode while Descending acquisitions are in SM1 (1.8m). SM1 data are therefore more suitable for offset tracking techniques (whose performances depend on reolution).

\subsection{Deformation mapping}

The following figures illustrate the main results obtained during this study. They consist in displacement rates (figures 2 and 4) obtained by stacking of interferograms and offsets estimated and their evolution (Figure 3 )

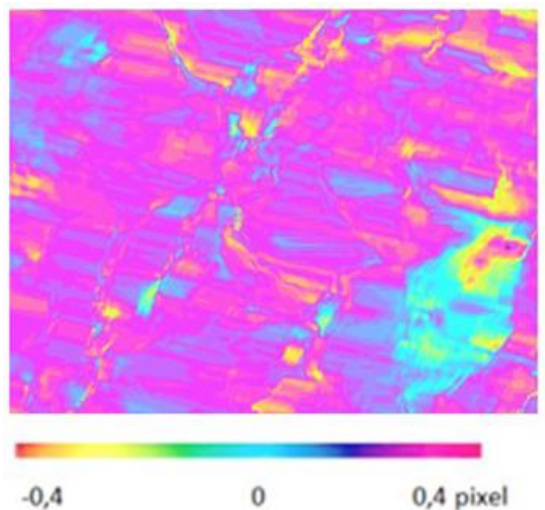

Figure 2: stack of offsets estimated along azimuth direction in pixel/yr (1 pixel=1.8m)

Remark: As shown on figure 2, the Hellbourg landslide has an important South-North horizontal component (about 7 times larger than the vertical component). The consequence is that a simple decomposition between vertical and horizontal components based only on Line-of-Sight from ascending and descending acquisition would fail (the resulting vertical component estimate would be incorrect).

\section{RESULTS}

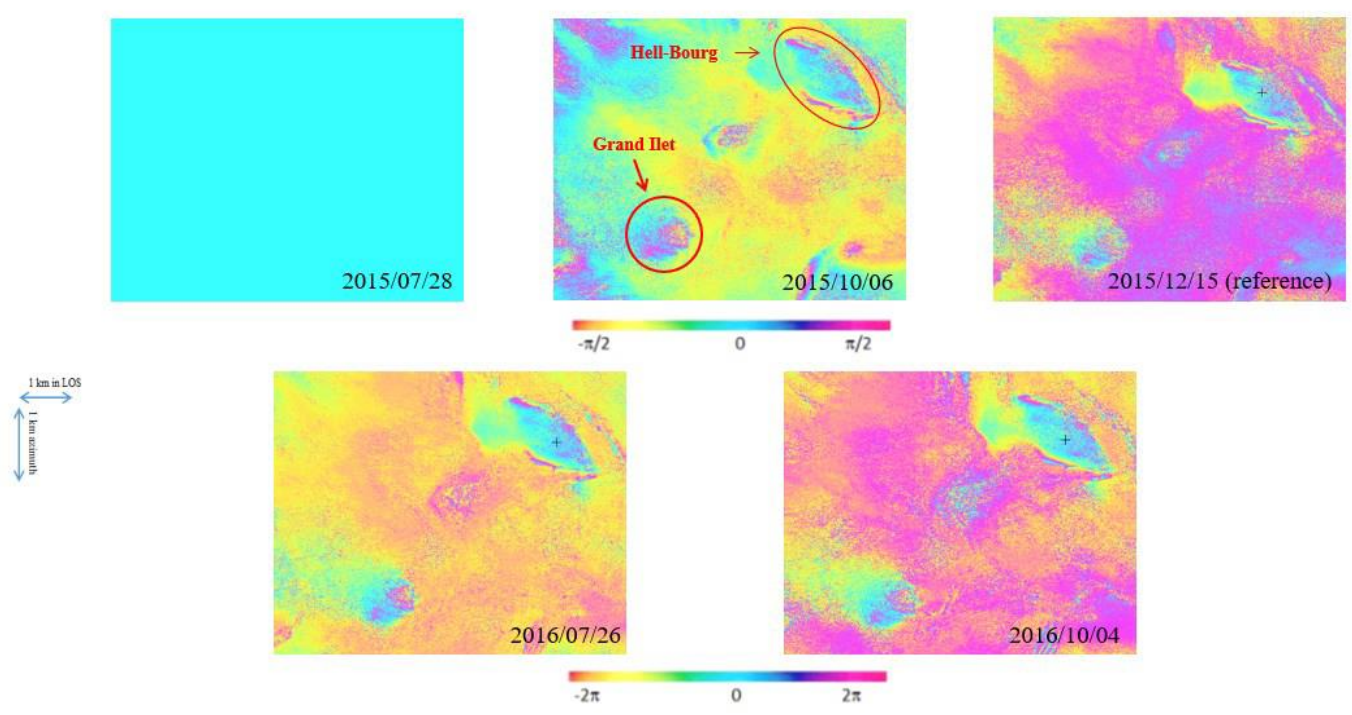


Figure 3: Evolution of Grand Ilet and Hell-Bourg Landslides observed using the ascending PALSAR 2 dataset (phase in radians).

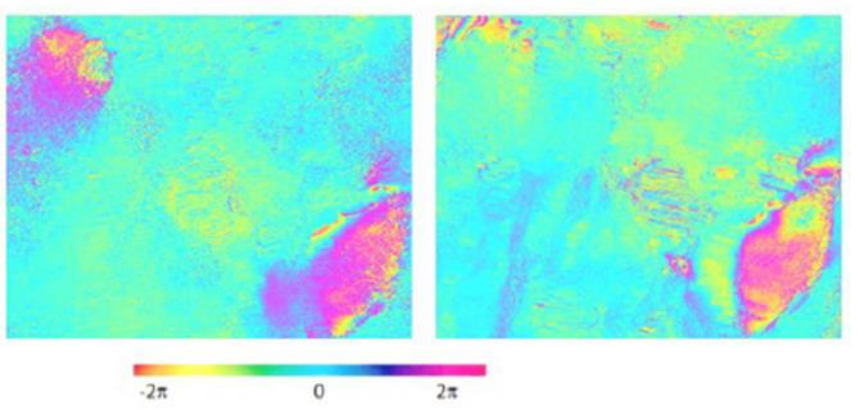

Figure 4: comparison Ascending (left) Descending (right) interferogram stacks on Hellbourg and Grand Ilet (cumulated phase in radians).

Finally Figure 5 shows a decomposition of the observed displacement on Hellbourg landslide.
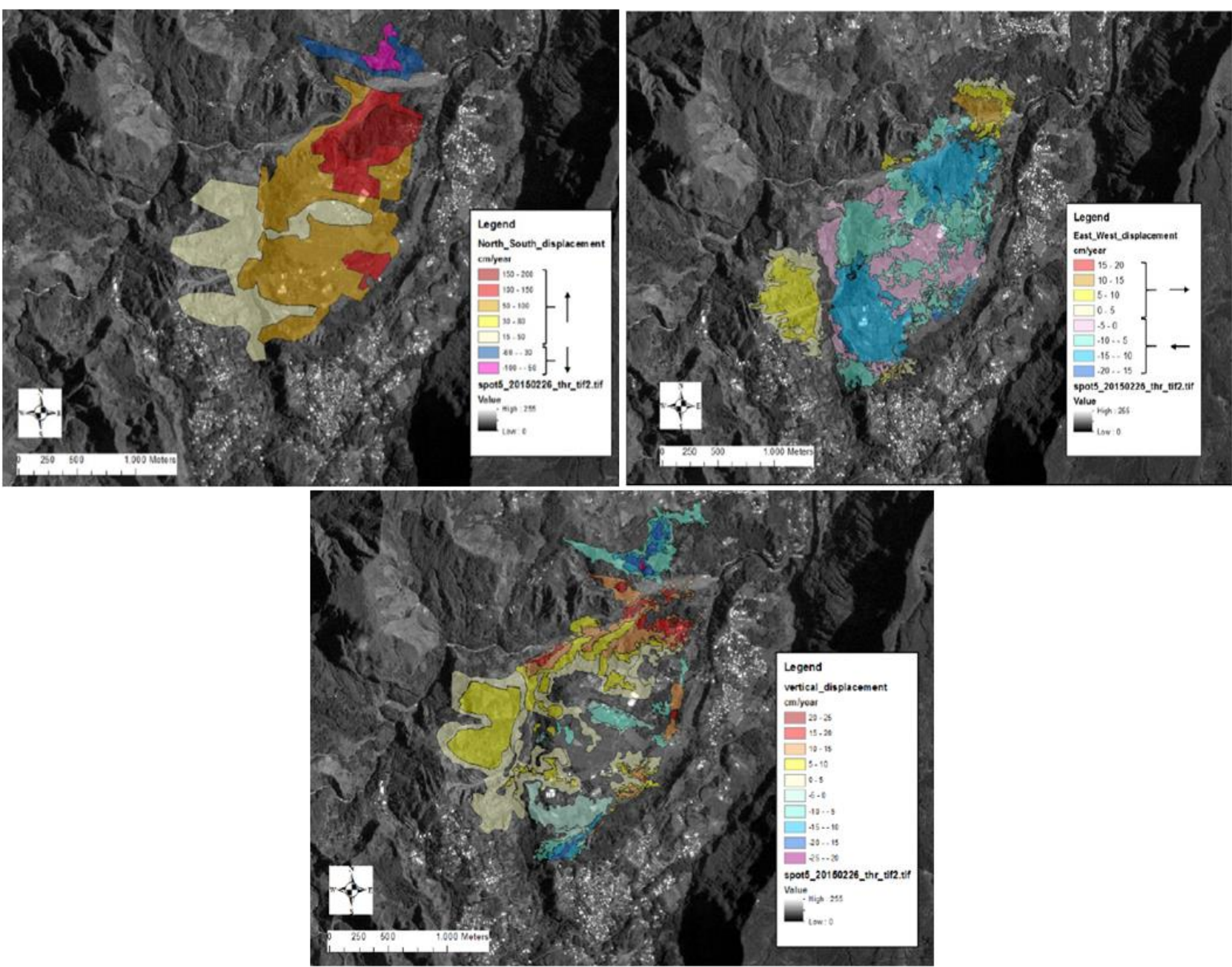

Figure 5: Hellbourg Landslide. Upper left: South North component of the displacement, Upper Right: East-west, Lower: vertical.

\subsection{Comparison with $\mathrm{C}$ band data}

Comparison with SENTINEL 1 interferogram stacks has been carried out. Due to the expected poor coherence on the test area, we processed only SENTINEL 1 interferograms with time spans shorter than 18 days in order to reduce the impact of temporal decorrelation. All the available SENTINEL 1 images available on the area during the period (end 2014-2016) were included in the computation. Results are presented on figures 5 and 6 . 


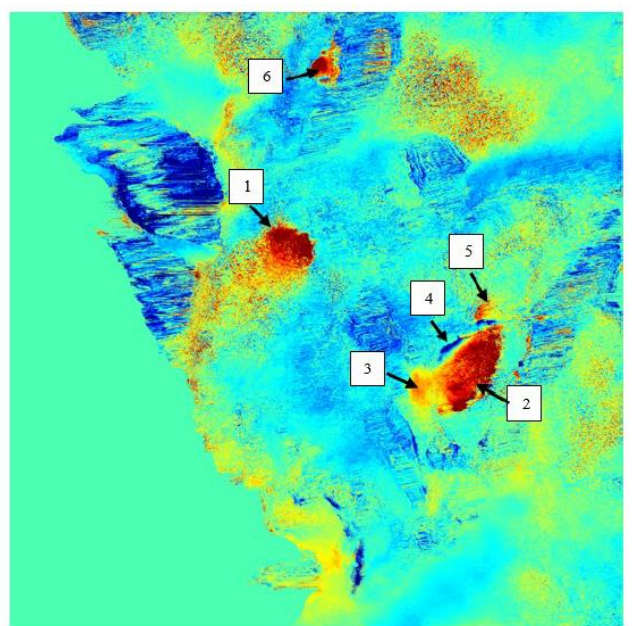

Figure 4 : ALOS-2/PALSAR-2 interferogram stack (ascending mode) main landslides are located.

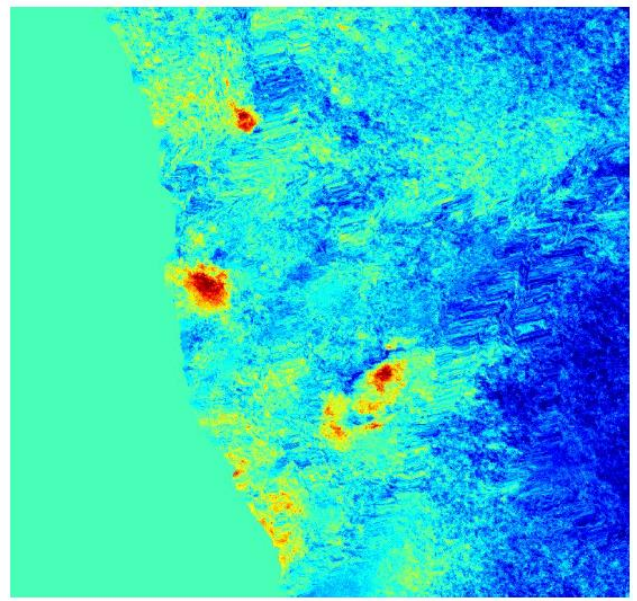

Figure 5 : Sentinel-1 interferogram stack (asecending mode)

Noteworthy is the fact that the main landslides of the area are identified on both interferogram stacks. However, the Sentinel-1 appears affected by temporal decorrelation even with very short time-spans reducing their interest (in particular for delimitating the landslides boundaries and panels.

\section{CONCLUSION}

These results show the interest of the specific characteristics of the ALOS-2/PALSAR-2 sensor for monitoring landslides in the context of La Reunion or similar (tropical climate, partly vegetated/partly urbanized cover). The interest comes both from the sensor's frequency (L band being appropriate for vegetated covers) and the fine resolution (increasing offset tracking performances). In further works we plan to deeper investigate the correlation of the observed displacements with the surface consequences (damages) occurred during the studied period.

\section{ACKNOWLEDGEMENT}

The authors wish to thank CNES (project KALIDEOS and Dr. Philippe Durand) for providing the ALOS-2 data on La Réunion Island.

\section{REFERENCES}

[1] Belle P., Aunay B., Bernardie S., Grandjean G., Ladouche B., Mazué R., Join J-L. (2013) - The application of an innovative inverse model for understanding and predicting landslide movements (Salazie cirque landslides, Reunion Island), 2014, Landslides, 11, 343-355.

[2] Delacourt, C.; Raucoules, D.; Le Mouelic, S.; Carnec, C.; Feurer, D.; Allemand, P.; Cruchet, M. Observation of a large-scale landslide in $\mathrm{La}$ Reunion Island using differential SAR interferometry (JERS and RADARSAT) and correlation of optical images (Spot 5), 2009, Sensors, 9, 616-630.

[3] Wakabayashi, H.; Nishio, F. Glacier flow estimation by SAR image correlation, Proceedings, 2004 IEEE International Geoscience and Remote Sensing Symposium (IGARSS '04), 2004, Anchorage, AK, 1136-1139.

[4] Hanssen, R.F. Radar Interferometry: Data Interpretation and Error Analysis, Kluwer Academic Publishers, vol. 2, p. 328, 2001.

[5] Raucoules, D.; de Michele, M.; Malet, J.F.; Ulrich, P. Timevariable $3 \mathrm{D}$ ground displacements from high-resolution SAR subpixel image correlation: Application to La Valette landslide (South French Alps), 2013, Remote Sens. Env., 139, 198-204. 